\title{
Journeying into the kinescape of unicycling: A Deleuzian perspective
}

European Physical Education Review $1-17$

(C) The Author(s) 2021

Article reuse guidelines: sagepub.com/journals-permissions DOI: 10.1 177/I356336X211065965 journals.sagepub.com/home/epe

@SAGE

\section{Håkan Larsson}

The Swedish School of Sport and Health Sciences, Sweden

\section{Gunn Nyberg}

Dalarna University, Sweden

\section{Dean Barker}

Örebro University, Sweden

\begin{abstract}
Movement learning has become a prominent issue in recent sport pedagogy research, including a particular concern about the new perspectives of movement learning. The turn towards new perspectives is partly spurred by discontent with the conventional perspectives of movement learning. The purpose of the article is to explore a journey into the kinescape of unicycling. The article can be seen as a case study of what it means to learn (how) to unicycle for one student teacher in the midst of a pedagogical research module and with the aid of the Deleuzian notion of a triadic relationship between percepts, affects and concepts. The analysis points to how a student, in the midst of material features such as equipment, the sport hall, other people, and instructional video clips, is mapping connections between concepts (what unicycling can be), percepts (a-ha moments) and affects (what moves him to continue practising unicycling), in ways that allow him to learn to unicycle with astonishing pace. His practising of unicycling is guided by particular strategies for exploration and experimentation that his experiences of board culture offer him. Rather than any general principles of movement learning, of importance here are the particular ways in which kinesio-cultural exploration may offer non-linear resources for movement learning. We conclude that this approach to learning may stimulate pedagogies that are not only effective but also more inclusive because they are more creative and more open than linear approaches to movement learning.
\end{abstract}

\section{Keywords}

Movement learning, unicycling, Deleuze, affects, concepts, percepts 


\section{Introduction}

Movement learning has become a prominent issue in recent sport pedagogy research (e.g. Barker et al., 2017; Whitehead, 2010). Much of this work includes a particular concern with new perspectives of movement learning (Larsson, 2021). The turn towards new perspectives is partly spurred by views that conventional approaches fail to fully explain movement learning (e.g. Aggerholm, 2016; Fusche Moe, 2004). Moreover, conventional perspectives in practice tend to contribute to the exclusion and marginalisation of some abilities and groups of people (e.g. Evans, 2004; Larsson and Quennerstedt, 2012; Tidén et al., 2017).

In a series of recent articles (Barker et al., 2020a, 2020b; Larsson et al., 2021; Nyberg et al., 2021), we developed a new approach to understanding movement learning called embodied exploration, where developing movement capability was seen as becoming familiar with movement landscapes. The notion of learning as 'familiarising oneself with a landscape', rather than 'climbing a ladder' or 'hitting a target' (step-by-step - linear - acquisition of knowledge), was borrowed from Hirst (2010). To further emphasise movement, or in Greek, kinesis, we have now chosen to shift from landscape to kinescape, and from embodied to kinesio-cultural exploration. Kinesio-cultural exploration involves exploring kinescapes, which 'have their own features and principles that relate to propulsion, flight, rotation and so forth. Principles are not only mechanical but also cultural and aesthetic as they encompass traditions and expectations' (Barker et al., 2021: 7). In this way, we hope to offer an understanding of movement learning and knowing that is not limited to 'step-by-step' approaches and narrow standards of excellence, and which can function inclusively.

In our previous work, we have drawn on theories of knowledge, or knowing, as formulated by Ryle (2009) and Polanyi (1998). This theoretical framework has allowed us to understand, in new ways, what it means to learn and know different movements and movement activities, such as juggling, unicycling and dancing (Nyberg et al., 2021). Researching movement learning has made us aware of the heterogeneity concerning not only how people learn new movements, but also the meaning of what is to be learned, the pace at which people learn and the importance of taking this heterogeneity into account when planning teaching (Barker et al., 2020a, 2020b, 2021; see also Beni et al., 2017; Fletcher and Ní Chróinín, 2021). Our investigation of pre-service physical education teachers learning to unicycle, for example, suggested that while some student teachers learned to unicycle in only a couple of hours, others still struggled to learn the basics of unicycling after 10 hours of practice, partly because of their fear of falling and hurting themselves (Barker et al., 2020b).

One of the students, Zack (pseudonym), managed to learn to unicycle in a fashion after the first two-hour session. After the second session, he managed to unicycle while simultaneously juggling with juggling balls. Zack learned to unicycle at an astonishing pace and in this article, we make a detailed exploration of his journey into the unicycling kinescape. Our general question in this paper is how to understand his rather amazing learning pace. The overall research project sets out to explore how new perspectives can bring new knowledge about movement learning to light. To find clues to Zack's learning process, we have found inspiration in the writing of French philosopher Gilles Deleuze and some of his interpreters in educational science, who offer a captivating entrance to questions about learning and knowing. Consequently, the purpose of this article is to explore how Zack, together with unicycles and other material features of the gym, and other people, including other student teachers, a teacher educator, and us (the researchers), journey into the kinescape of unicycling. The article can be seen as a case study of what it means to 
learn (how) to unicycle for one student teacher in the midst of a pedagogical research module and with the aid of the Deleuzian notion of a triadic relationship between percepts, affects, and concepts.

\section{A pedagogy of the concept: Percepts, affects and concepts}

Despite never having written a book about learning, parts of Deleuze's oeuvre include philosophical expositions about precisely this issue. As Cole (2016) asserts, Deleuze 'provides an integrated theorisation of learning without having written specifically on education' (p. 1). In fact, Deleuze used movement knowledge to outline his perspective of learning, namely swimming capability (Deleuze, 1994: 165). ${ }^{1}$ In a discussion of the swimming learning example, Bogue (2004) emphasises that learning in a Deleuzian perspective does not necessarily follow any pre-established pattern; it is non-linear, or in Deleuze's terms: rhizomatic. Learning to swim can be likened to an apprenticeship in signs (Deleuze, 2000) where learners interpret signs, such as the carrying capacity and resistance of the water, and how the body's movements in the water contribute to movement through the water, which enable them to find their own solution to the problem of swimming. Signs, however, 'are not transparent media for the communication of information' (Bogue, 2004: 327). Rather, they are enigmatic. Like hieroglyphs, they 'point beyond themselves to something hidden' (Bogue, 2004: 327). The carrying capacity of water, for example, is not necessarily obvious to someone who ventures out into deep water. Returning to the notion of the triadic relation between concepts, percepts and affects, our understanding is based on the idea that the interpretation of enigmatic signs contributes to the formation of concepts with the learner, which are how learners conceive what the object of learning is about, or more simply, what learners know about the object of learning.

The triadic relationship between concepts, percepts and affects has been theorised more extensively by Semetsky (2007), one of the leading Deleuze experts in educational science. Semetsky's account is based on Deleuze and Guattari's (1994) notion of 'a pedagogy of the concept', where concepts are 'created as a function of problems which are thought to be badly understood or badly posed' (p. 16). Thus, rather than focusing on what concepts mean 'once and for all', concepts are temporary tools that are produced by learners to understand and learn new things. However, the process of concept production must always be related also to percepts and affects: 'we need all three to get things moving' (Deleuze, 1995: 165; original emphasis).

Concepts designate what learners know about some things, but concepts are not homogeneous and finite. They are always ambiguous, temporary and in the making. Deleuze (1994) writes that concepts can be seen as encounters with here-and-now, "from which emerge inexhaustively ever new, differently distributed "heres" and "nows" [...] I make, remake and unmake my concepts along a moving horizon' ( $\mathrm{p}$. xx-xxi). Thus, concepts designate what can be; concepts are the way learners try to represent what is learnt as a result of sense-making.

Sense-making takes us on to percepts, which designate the sensations that separate some things from something else. Or as Semetsky (2009) puts it, percepts are always 'perception in becoming. New concepts will have been created when one's perception undergoes a transformation' (p. 448). Thus, concepts cannot be produced without sense-making. Percepts fold back onto the learner to produce embodied sensations - at best, they are a-ha! moments - in which learners perceive the transformative process that occurs during experimentation with the real. In this sense, percepts are what produce sensations and perceptions of transformation.

Affects, finally, can be described as a capacity (Safron, 2020a, 2020b): 'the body's capacity to be moved and be affected, and the body's capacity to move and affect other people and other things' 
(Vannini, 2015: 9). It is the interaction between percepts and concepts in becoming that produces affects that have the ability to amplify - or curtail - the body's capacity to act in particular ways.

The creation of concepts takes place in a repetitive process, where repetition should not be interpreted as 'a reproduction of the same (as is the case in linear approaches to learning; authors' note) but a repetition of the different' (Deleuze, 1988: 98). Thus, rather than 'nail down' a specific movement pattern (and achieve 'automation' in a linear sense of learning), repetition involves what could be termed oscillation, that is, a movement back and forth in a non-linear process, where repetition of differences contributes to increased sensibility (percepts) among learners, which opens up new options for action. Moreover, Deleuze (1994) stresses that learning always takes place 'in and through the unconscious' (p. 165). We are aware that Deleuze was also critical of Freudian psychoanalysis (Deleuze and Guattari, 2013); thus, we assume that what is here referred to as 'the unconscious' is not to be seen as an underlying governing structure. Rather, we assume that the unconscious can be likened to what Polanyi (1998) termed subsidiary awareness, that is, the parts of perception that are in the background (while focal awareness points to what is in the focus of perception). As Cole (2016: 2) emphasises:

the unconscious does profoundly synthetic and positive, i.e., paradoxically conscious, work according to Deleuze, through the clashing of affect and the playing with chaotic material processes through, for example, creative experimentation. The unconscious is in the Deleuzian frame a creative and vital cauldron of new thought.

We believe that Deleuze's rhizomatic perspective of learning has much to offer when attempting to understand the processes of movement learning. Learning to unicycle can be likened to a process where learners decipher unicycling hieroglyphs whose meaning is not immediately accessible. It can be seen as a mapping of a unicycling kinescape. The ongoing mapping/deciphering of signs contributes to re-conceptualisations of what unicycling capability means; it expands and nuances features of the unicycle kinescape. Unicycle capability must be at the same time discovered and invented by the learner. The double process of discovery and invention is necessary precisely because the meanings of the signs need to be actively brought into existence in their own unique ways by the learner. Learning to unicycle, then, is not learning the same 'thing' for everyone; it is about learning in a particular way to master a capability in a particular way. In this article, our focus is on Zack's mapping of his unicycling kinescape.

\section{Method}

Zack participated in a project where we invited 25 physical education teacher education (PETE) students at a university in southern Sweden to learn to unicycle while we documented the process. The selection of students was based on which students were available and chose to volunteer in the project. We had no intention to measure any specific learning outcomes, nor compare different groups of students or pedagogical approaches. Instead, we focused entirely on the qualitative aspects of the learning processes, which were taking place in a five two-hour session module that was based on the notion of kinesio-cultural exploration. This meant that particular interest was paid to how the students approached the task of learning to unicycle, their focus of attention, and what unicycling, or learning to unicycle, meant according to their experience. Our analytical interest fell on Zack because he learned to unicycle with what we perceived as an astonishing pace. In fact, our choice was motivated by our impression that 'learning' is used in physical education 
research in a rather general sense, often without considering the 'what' of learning (what is in educational contexts sometimes referred to as the learning object) (Nyberg and Larsson, 2014). In the Deleuzian approach, although attention is primarily on the process of learning (how), the what of learning is not neglected since there is a clear focus also on concepts. However, the Deleuzian approach makes clear that while a learning object, such as unicycling, is nominally the same, in reality, it may mean slightly different things for different learners.

\section{The module}

It should be noted that the study was designed well before we found inspiration from Deleuze. However, after having consulted several publications about Deleuze inspired methodologies (e.g. Coleman and Ringrose, 2013; Landi, 2019; Lupton, 2021; Safron, 2020a, 2020b), we believe that our original methodological approach sits comfortably with a Deleuzian inspired analysis. We acknowledge that as researchers, we are indeed ourselves very much entangled within the very processes we wish to study (Coleman and Ringrose, 2013). This is mirrored also in how we view data production and analysis. In the following, we will describe how we arranged a pedagogical module where student teachers had the opportunity to practise unicycling and where the research data was generated.

The project was action-oriented in the sense that we created a pedagogical module, which was originally based on our interpretations of Ryle's (2009) and Polanyi's (1998) writings about 'knowing how' and 'knowing'. Our aspiration was that the module would allow for kinesio-cultural exploration among participants. We invited a PETE educator who knew the group well to assist with the implementation of the module. Some days before the module started, researchers provided students with a number of YouTube clips about unicycling, some of which had an instructional character, suggesting ' $\mathrm{x}$ steps on how to learn to unicycle', while others displayed impressive tricks that one could do on a unicycle. Since we planned for kinesio-cultural exploration, which could include exploring different 'learning paths', the students were invited to select a clip that they thought could help them learn and had the opportunity to discuss the selected video-clip with peers during the first session's initial group discussion. The five two-hour sessions took place over one week. The first session commenced with a group discussion, where groups of three to four students talked about their expectations prior to starting the unicycle practice.

During the practising, students were asked to work in groups of two or three with the aim of assisting each other to the best of their abilities. There was a minimal amount of direct instruction from the researchers and PETE educator, although some advice was offered to prevent accidents. Practice was interspersed with moments where the students were asked to document reflections of their learning processes on their smartphones; documentation was submitted to us at the end of the module. We encouraged the students to reflect on their kinesio-cultural exploration, that is, their approach to the task, their attentional focus and their subjective meanings of unicycling. Additionally, we asked the students to note what they found easy or difficult, and the things that they thought had helped them in their learning. They could also include notes about their mood during the sessions. We encouraged a culture where learning to unicycle was highly valued, simply because there can be no learning without this verticality (Aggerholm, 2016). However, we were also mindful about the possibility of social comparison (i.e. competition) between the students which can be both beneficial and an obstacle to learning. Thus, we emphasised that our focus was on individual progression. Moreover, we endeavoured to encourage and celebrate progress, rather than learning more quickly than one's peers (i.e. 'winning'). Nevertheless, it was clear to 
us that some students discontinued because they experienced limited progression in relation to their peers.

We had a gym hall measuring approximately 40 by 20 meters at our disposal. The researchers and the PETE educator brought out equipment that could be used for physical support, such as booms and plinths. The students could also use the walls or the wall-bars for the same purpose. Additionally, the students were free to use any other available material that they thought would help their learning.

Some students assisted each other by providing physical support, filming (with the use of their own mobile phones) or making suggestions about what to try out or what equipment to use as aids. Nevertheless, the amount of verbal communication in the groups was less than expected, despite our emphasis on the importance of communication. While some students chose to stay in the groups that we organised, others formed new groups or pairs, and a few seemed to prefer to practise alone.

In sum, the way we arranged the pedagogical model mirrors the messy entanglement in the research process between student teachers, of which Zack was one, teacher educator, researchers, unicycles and other equipment, the material features of the gym hall, YouTube clips, and more.

\section{Data production and analysis}

We used multiple means of data generation. In previous publications (Larsson et al., 2021; Nyberg et al., 2021), we have described the data collection as ethnography-inspired (Nova, 2014), including participant observations (Angrosino, 2005) and ethnographic-type conversations (Spradley, 1979). This meant that throughout the practice sessions, one of the researchers took notes while the other two wore GoPro cameras mounted on their chests. Taken together, the notes and the approximately $40 \mathrm{~h}$ of video recordings offered a useful means to provide thick descriptions of learning processes. Ethnographic-type conversations (Spradley, 1979) took place when the researchers approached students with questions such as, 'what happened here?', 'what is difficult in this activity?' and 'what helped you accomplish this?' These conversations typically lasted from a few seconds up to a couple of minutes. We also encouraged the students to write about their learning processes in learning logbooks.

The article focuses on Zack's learning process, specifically what took place during the first two practice sessions. Although we soon realised that Zack was learning fast, we could not anticipate his or any other student's success (or failure) in learning to unicycle. This means that the initial stage of analysis is best described as a post hoc search in the data material for information about Zack's learning process. Fortunately, there was ample video footage of him practising on the unicycle, using different equipment as support, talking to peers, the teacher educator and us. Additionally, Zack was systematic about writing in his learning logbook during the sessions. When asked to respond to our questions during the practice, he seemed to prefer to show us with the help of the unicycle rather than using words. Thus, the analysis is based mainly on the video observations of Zack's practice, his conversations with peers and his written notes, and only marginally on interviews with him during the sessions.

Analytically, we have aspired to follow Mazzei and McCoy's (2010) suggestion to 'think with Deleuze'. We assume that this means, as Coleman and Ringrose (2013) assert, that the Deleuzian concepts are creative rather than representative, reflective or descriptive. '[A] concept is neither a pre-existing theoretical framework into which empirical material is fitted and interpreted, nor a notion that springs from empirical research [...]. Rather, concepts do things' (Coleman and Ringrose, 2013: 8). Our aspiration in the findings section is to explore how Zack journeys into 
the kinescape of unicycling in the midst of a pedagogical research module and with the aid of Deleuzian thinking.

\section{Who is Zack?}

During the module, we got more and more glimpses of Zack's previous movement experiences and lifestyle. We learned that he had practised a lot of acrobatic movements, such as balancing on a slackline and riding different sorts of boards. Through researching his background on the Internet, we realised that he had been a semi-professional wakeboard rider. This background may help explain why the 'flashy' commercial YouTube clips of spectacular unicycling were more enticing to Zack than the pedagogical step-by-step clips targeting novices. He never expressed doubt about his ability to learn to unicycle. It was not a question of if he could learn to unicycle, it was more about when or how fast he was going to learn, and what his learning would enable him to do. Even though Zack practised on his own for the most part, he clearly carried with him earlier experiences of learning movement skills. Our interpretation is that Zack in the context of unicycle practising managed to draw creatively and constructively on his experiences of board culture, where he had previously learned to approach movement learning autonomously as an explorative, experimental and non-linear process, without the presence of experts in the form of coaches, instructors or teachers nor expert peers (cf. Bäckström, 2014). While Zack did not know at the outset exactly where to go and what to look for, he realised that he needed to search for signs that could function as indicators that directed his practising towards the capability of unicycling, or his mapping of the unicycling kinescape.

\section{Findings}

The findings are organised according to the ideas of the triadic relationship between affects, concepts and percepts, which helped us in the analysis to creatively get entangled in Zack's exploration of the unicycling kinescape. First, however, we want to highlight Zack's rhizomatic process.

\section{Rhizome}

Zack's overall experience of mapping kinescapes made him realise that he needed to search for signs that could function as indicators that directed his practising towards the capability of unicycling. As we will soon illustrate, from the start of the module, he appreciated that he knew both that he needed temporary concepts based on which he could initiate the practising and that he needed to be open for continuous re-conceptualisation when he discovered that his attempts on the unicycle did not turn out to be exactly as he had anticipated. However, that is not all. He also seemed in some way to be aware that he should not 'get stuck' in what could be termed repetitive practice.

On many of the occasions when the video camera captures him, Zack can be seen practising intensely, but not for too long with one and the same thing. He seems to have embodied a strategy where he with some regularity alternates between practising on the unicycle and reflecting (e.g. by writing in his learning logbook) as well as switching between various 'exercises'. However, there was no apparent scheme or structure to the practice. Instead, this oscillating between different ways of practising and reflecting (Nyberg et al., 2021) appear to be guided by non-linearity. Zack seems to assume that the exercise should be varied, but what ultimately determines the next step depends on what he thinks he is about to discover in the unicycle landscape. 


\section{Percepts}

Percepts are about a-ha moments in the practice; moments where learners manage to make (new) sense of something that was previously insignificant. Throughout the module, Zack was very attentive to what happened when he mounted the unicycle. His rich experience from wakeboarding and other activities 'on unstable ground' offered him some means to be attentive to certain clues (signs) that the repeated practice on the unicycle engendered. Moreover, both his intrepidity and his self-description as an 'acrobatic' person (also acknowledged by his peers) were helpful in his endeavour to learn to unicycle. His mapping of the unicycling kinescape was very active and autonomous in the sense that he did not expect anyone else to tell him or show him how to unicycle. After initial experimentation, his attentiveness was primarily directed to keeping balance through gaining speed. He did not need to divert his attention, for example, to what would happen if he fell off, or whether his undertaking seemed peculiar in the eyes of his peers:

Ben: I think it's important to dare a little too, that one can be a little afraid of falling and so on. [...] I think, you're a kind of daring person, aren't you, eh ... but that's probably because you have the selfconfidence ... compared to some others then (laughs).

Zack: Yes, it helps a lot not to think about consequences.

Ben: No, I'm thinking, 'shit, I'll fall and hit myself', like.

Zack: You solve it when it comes ... [...] It's just reflexes ... and they improve every time you fall. [...] The body doesn't want to hurt itself. You'll ... adapt. It's mostly the thinking that makes you hurt yourself ... I think.

In this quote, Zack indicates that much of the learning takes place in the unconscious, or to use Polanyi's (1998) terms, as phenomena that were initially in the focal awareness shift to the background, that is, to the subsidiary awareness. In his reflective notes, Zack writes:

When I practise balance, I see it as if I spend time with my body and I have a pretty intense conversation with it. (Day 1)

To be honest, I think as little as I can when it comes to balance because thoughts disturb the bodily focus. I think through my body. An example of this is that I can, for example, be influenced by a comment where someone cries: 'well done, all the way now' and the same second I fall off. The bodily focus disappears and the mental takes over. (Day 2)

Throughout the module, Zack preferred to practise in solitude. Perhaps this can be seen as an attempt at not being 'disturbed' by things that would call for his attention. Practising alone, however, is not tantamount to practising in a sociocultural void. In different ways, Zack embodies cultures in which he has previously been immersed.

Zack's initial focus on balance, along with his rather sophisticated exploration and experimentation strategy, enabled him to quickly arrive at an a-ha moment. Already during the first practise session, he realised that he should not focus too much on balance in itself, but rather on forward momentum, where balancing became an aspect of forward momentum. In a small group discussion mid-way through the first session, Zack said to Mel and Ben: 
Yes, but now I had it. It's just ... It's a lot about just pedalling. I realised that, the faster it goes, the more balance you get ... and ... when you've picked up speed ... it was pretty easy. [...] I think you feel it very clearly, when you lose balance, it becomes very natural to just (makes a forward gesture with his arm).

Later on, Zack arrived at more a-ha moments. During the second practise session, one of the researchers asked Zack about some aspects of the unicycling capability:

Researcher: How is the weight distributed? Is it the same on the saddle and pedals?

Zack: Yes, you sit and you feel how you are straight over the bike. And then you try to get the centre [of gravity] to point just a little bit forward.

Researcher: Okay, a little forward. But the load, is it equally distributed on the saddle and each leg? Zack: Mm (positive sounding), and it shouldn't be much on the legs. That's when it stopped.

Zack is here referring to one occasion where the acceleration phase got jerky because of tensions in his hip and upper leg muscles. Clearly, Zack is attentive not only to what he perceives while attempting to unicycle, but also to the meaning of what he perceives - and how constructing new meaning may alter what he perceives, in an endless process. His strategy seems to be to deliberately shift his focus of attention from what he is doing to where he is going. Above, Zack emphasised how he challenged himself with doing increasingly complex exercises. Many of these challenges seemed to be about shifting focus away from what he is doing to where he is going.

Zack: And so I want to try to stay in line. I was disturbed by having people in front of me. So, I was interrupted. So ... clear view, something to look at, lean forward and then ... (makes a forward circular motion with his hand).

On one occasion, he moved the plinth to be able to start unicycling in line with one of the lines on the hall floor. Alternatively, while seated on the unicycle he gazed intensely at the wall at the other end of the hall, some 40 metres away. However, Zack had more 'tricks' with which he tried to shift his focus away from the cycling itself. He filmed himself with his mobile phone while cycling, then looked at the films between his trials with the unicycle. He even brought three juggling balls and tried to juggle while cycling. When asked why he uses these 'tricks', his reply further emphasises his need not to be distracted by what he is doing:

Zack: It's for me to let go of my legs. The more you let go of your legs, eeh ... the easier it gets.

Researcher: Yes (several seconds of silence). What do you mean by letting go of your legs?

Zack: I think, a lot is instinctive. That ... you get scared of falling.

Researcher: Yes, yes, okay, so you mean, don't control your legs too much. Your legs should ... work independently, so to speak.

Zack: Yes, exactly. They have to ... get started, like.

Researcher: Yes, I understand.

Zack: ... that ... in the beginning it becomes very much that you ... (shows that the pedalling goes sluggishly, stops)

Researcher: Yes, that's right.

Zack: So I feel somewhere here, like, I feel that I have to ... let the leg work itself ... and so ... yes ... you notice more and more how relaxed you become.

Zack's explanation could be interpreted in the sense that he is trying to 'automatise' the movements. 
Based on Deleuze's theorising, his endeavour can be interpreted, rather, as a way of letting the body (the unconscious/subsidiary awareness) do the deciphering, while the attention (the conscious/focal awareness) is directed towards a goal that is external in relation to his way of cycling.

\section{Concepts}

Concepts are in this study about what unicycling can be. It is apparent in Zack's account that he did not start practising with a blank slate. He had some idea about what it could mean to (learn to) unicycle, and this idea was based on his previous engagements with acrobatic movement activities. To begin with, he focused primarily on 'balance'. In the initial group discussion, he emphasised that it is 'just about trying to come up on it and try to find the balance'. Moreover,

[m]y picture is pretty clear about how I should go about learning ... eh, it feels like I ... visualise the feeling ... in balance, how it works ... because I have done a lot of balance exercises before, so I think I can wrap my head around it. (Day 1, initial group discussion)

In his written notes, he acknowledges his previous movement experiences, noting: 'I would say that slackline, wakeboard and trampoline help me with balance' (notes, day 1). Thus, to learn new movements, it seems important for Zack to get an initial idea of what a movement may mean. Apparently, balance is a key in Zack's initial unicycling concept. At the same time, he realised that during the process of mapping, it may be necessary to be able to abandon this initial concept, or at least re-conceptualise it, for example, through altering certain features of the initial concept. Even on the first day, after practising for approximately an hour, Zack wrote that: 'It [learning to unicycle] was a little different than I thought at first My notions before the practice was that I could close my eyes and feel how it would feel in my body. I knew from before what it would be like to keep the balance. [... However,] I quickly realised that I need speed to get ahead, where the first two pedal turns must work smoothly, without resistance'. Hence, the initial practice meant that Zack incorporated forward momentum into his temporary concept of balance.

Zack: Now I understand how it works. Now it's just about getting going. I will learn this in another 15 min.

Researcher: Is that how it feels?

Zack: Yes, now I have it. It's just ... It's a lot about just pedalling. I realized that, the faster it goes, the better balance you get.

However, there were more problems with Zack's initial concept:

Zack: It was harder than I thought.

Researcher: Did you discover something unexpected?

Zack: Eh ... yes ... well that's it, I wish that the wheel could roll without me having to pedal. I feel that's an obstacle.

Researcher: The acceleration phase gets choppy?

Zack: You want to keep your balance and that's what happens (makes a jerky motion forward and back with his upper body). It can be a completely opposite movement.

Our interpretation of Zack's commentary is that his unicycling concept is influenced by what it is like to ride a bicycle which has a freewheel function, that is, where it is possible to pedal backwards 
or stop pedalling and still continue to roll forwards. Hence, likening unicycling too much to bicycling can contribute to difficulties in learning to ride a unicycle.

Towards the end of the first session, the video-clips show Zack attempting to pedal away from his support as swiftly as possible. He leans forward markedly, and it is apparent that he aspires to gain forward momentum. He manages to cycle 10 metres, 20 metres and 40 metres (across the whole gym hall). Every time he falls off the bike, he rapidly picks it up from the floor and jogs back to the starting position. His mode of practising is intense in comparison with most of his peers.

During the module, the researchers and the PETE educator introduced some challenges. For example, we encouraged the students to set up cones and try to slalom. We also showed them a YouTube clip with Japanese kindergarten children who were holding hands and spinning with each other while unicycling. In his written notes, Zack responded to the question 'How did these challenges affect you?' in the following way: 'I don't think they affected me that much. I create my own goals and visions. [...] I challenge myself by doing more and more complex exercises' (day 4). We believe that these statements about self-imposed challenges mirror Zack's support from a board culture (cf. Bäckström and Sand, 2019). Moreover, they point to the third axis of the triadic relationship between percepts, concepts and affects.

\section{Affects}

Affect is the creative force in learning processes. Affects propel events into existence (Hickey-Moody, 2013; Safron, 2020a, 2020b). Already at the outset of the module, it became clear that Zack had a hunch, a visceral prompt (Hickey-Moody, 2013), that he could learn to unicycle quite easily. The beginning of the pedagogical module was not strictly the origin of the learning process for any of the students, because no-one starts practising with no preconceptions. However, it soon became clear that Zack differed from many of his peers regarding his approach to the endeavour. While this could be seen as an indication of Zack's learning style, with a natural focus on experimentation and rhizomatic mapping, the opportunity for Zack to practise in this way in an educational context seemed to amplify his capacity to act in particular ways. The following dialogue unfolded during the first session's opening group discussion, where the students discussed their selection of an inspirational YouTube clip:

Three students, Zack, Mel and Ben, and a researcher discuss some of the YouTube clips that were offered by the researchers. While Mel and Ben have selected what can be designated instructional clips, Zack has selected a commercial style clip where two young persons, a man and woman, demonstrate advanced skill and tricks.

Zack: I have chosen this one, because then I realise ... what you can do when you know it.

Ben, responding to what he sees in the YouTube clip: I'm just almost like ...

Mel: ... horror-struck (laughter)!

Ben: Just ... would kill me!

$[\ldots]$

Researcher to Zack: But why did you choose that clip then?

Zack: Because once you have learned, you can do so much more ... you can do many different things.

While Mel and Ben seemed to look forward to the practice itself, albeit with some apprehension, Zack seemed to be exhilarated and spurred by what he would be able to do. Hence, already at the 
outset, rather than (the) learning (process), his eagerness was directed to what he will be able to do further on. Important to note is that while it seemed obvious to Zack what he would be able to do, few other students voiced such thinking. As with Mel and Ben, for many students, factors associated with challenge such as the support they needed, the patience required, avoiding injury in the case of falling, were in focus. What it would mean to be able to unicycle rarely surfaced among other students. Having said that, it should be noted that we explicitly focused on the practising and exploration rather than on what the student teachers would or should be able to do at the end of the module. Nor did we hold out any prospect about what could happen after the pedagogical module was finished. This only emphasises Zack's readiness to make the endeavour his own.

Zack's wish to learn is also related to his understanding of himself as someone who is movement capable. In his initial notes in the learning logbook, he wrote: 'I feel excitement and that it will be fun to try something new. My expectations are that I will be able to do it relatively easily because I have practised balancing a lot before' (day 1). This expectation was shared by Mel and Ben, who suggested that it was Zack's 'style' to learn balance tasks quickly. Mel and Ben's comment about Zack's style made us curious about Zack's previous movement experiences.

In our videos, it is easy to discern the eagerness in Zack's more or less independent approach. Frequently, he can be seen propelling his way from his initial support - often a plinth, out on the gym hall floor. When he half falls, half jumps off the unicycle, he rapidly jogs back to the plinth carrying the cycle. In his notes during the second session, he writes: 'I felt an inner joy and just couldn't stop. I eagerly ran back to try again. Of course, I also feel frustration sometimes, but I can control it through active choices and turn it into motivation. [...] When something goes wrong, it's easy to question oneself. But instead of thinking "why?", I think "how do I proceed?", (day 2). ${ }^{2}$

Arguably, the frustration that Zack sometimes feels can actually be seen as an appropriate element in the learning process in the sense that it indicates that Zack is 'almost there'. However, the emphasis on 'how to proceed' - or mapping - rather than getting preoccupied with what does not work, is an indication of his rhizomatic mapping, which includes an inclination to oscillate (Nyberg et al., 2021) between different ways of practising. He oscillates, for example, between different types of support, different ways of gaining momentum (pushing with the arms, pedalling with the feet), and breaking up the unicycle practice with writing notes. Moreover, his notes reveal important aspects about the sociocultural context, and the way in which peers sometimes compare themselves with others, for better or worse: 'When looking at others, look at technique and not level', Zack suggests. 'Comparing oneself affects your self-confidence. Be curious about what others are doing and not about how good they are' (day 2). Apparently, Zack's movement biography allowed him to approach a challenging motoric task without 'getting stuck' and without being concerned for others' level of mastery.

\section{Discussion and conclusion}

The purpose of the article was to explore, with the aid of Deleuzian theorising, how Zack journeyed into the kinescape of unicycling. Zack's rhizomatic mapping of his unicycling kinescape illustrates the non-linear relationship between concepts, percepts and affects. Each aspect undergoes reconstruction as Zack revises his unicycling capability through experimentation and sense-making. If one aspect changes, the other two aspects change too. He understands unicycling as something, but he is constantly open to changing his concept of unicycling. For example, he quickly realised that, for him, balance is primarily an aspect of forward momentum and not important in itself 
(concept); he reached this insight (a-ha moment) rapidly because he was skilled at distinguishing relevant features of the practice (percept); and the a-ha moment also spurred continued practice (affect). Accordingly, rather than successfully tracing the inherent 'correct' features of unicycling, Zack continuously (re)invented his own personal unicycling concept. Overall, we believe that Zack's practising offers a vivid illustration of what Bogue (2004), drawing on Deleuze, meant by 'genuine learning':

Genuine learning involves an engagement with such problems, a reorientation of thought following its initial disorientation, such that thought may comprehend something new in its newness, of knowledge to be mastered. (p. 340)

In a similar vein, Semetsky (2007: 201) holds that Deleuze saw 'genuine education' as 'a deregulation of the senses and a shock that compels thought against its will to be beyond its ordinary operations'. This 'reorientation of thought following its initial disorientation', that is, the 'shock', indicates Deleuze's rhizomatic perspective to learning, where learning is about drawing lines between connections (Grossberg, 1997). Hence, Deleuze's perspective stands in stark contrast to the perspective of linear learning, but it also differs from other non-linear learning theory (e.g. Davids, 2010; Jess et al., 2011) in the sense that it emphasises the blurred boundaries between objective and subjective. Movement learning is not about merely detecting a priori detectable features of any given movement, which supposedly lay ready to be discovered by learners. Of course, there is something to discover, but the enigmas of any movement or movement activity to be learnt must also be actively invented by the learner because knowing is always personal (cf. Polanyi, 1998). Zack learned (how) to unicycle with astonishing pace not because he discovered the correct signs of unicycling that lay dormant in the practice, but because he let himself be shocked, so to speak, in ways that enabled him to actively (re)invent his personal unicycling concept over and over again during his enduring and intense practising.

Furthermore, we believe that Zack was successful in his unicycle trials not just because he is a 'motoric person' who learns fast. Rather, he is 'motoric' because he knows how to use the tools that his experiences of movement learning offer him in explorative situations. In this sense, one might say that our encounter with Zack, who in turn managed to approach the task of learning to unicycle from a kinesio-cultural exploration approach, was serendipitous. The 'I can do it approach' is highly valued within board culture, which includes 'exploration of kinaesthetic experience' (Bäckström, 2014: 758). Some students in the group, who had competitive sports backgrounds, struggled more with the explorative approach. During the sessions, these students even lightly admonished us for not being able to instruct sufficiently, indicating that they valued, or at least were familiar, with coach- or teacher-led instruction.

We want to provide a word of caution: in the introduction, we justified the development of new perspectives of movement learning by proposing that conventional perspectives may contribute to exclusion and marginalisation of some abilities and groups of people (e.g. Larsson and Quennerstedt, 2012; Tidén et al., 2017). At the risk of sounding repetitive, it is important to emphasise that while Zack offered us indications of how he learned to unicycle, we are not claiming that this is what learning to unicycle is generally. Rather, Deleuze's rhizomatic account helped us understand that there are many ways to learn to unicycle. Moreover, being able to unicycle is not one and the same thing for everybody. Zack pointed to one way among many of both learning and knowing unicycling. In saying this, the triadic relationship between affects, concepts and percepts could probably be a useful tool with which to explore learning more generally. It will allow for a 
multilateral understanding of learning, including, for example, that which is conventionally called 'motivation' not only affects the willingness to participate and make an effort, it also affects the way the learner perceives and conceptualises what is to be learnt.

Many commentators maintain that Deleuze's perspective engenders new and different ways of thinking about pedagogy (Bogue, 2004; Cole, 2016; Lea, 2009). For example, Deleuze (1994) emphasises that "We learn nothing from those who say: "Do as I do". Our only teachers are those who tell us to "do with me", and are able to emit signs to be developed in heterogeneity rather than propose gestures for us to reproduce' (p. 23). Bogue (2004: 340-341) expands, suggesting that:

[o]ne cannot teach the truly new in its newness, but one can attempt to induce an encounter with the new by emitting signs, by creating problematic objects, experiences of concepts. Hence, the pedagogy of signs entails first a critique of codes and conventions, an undoing of orthodox connections, and then a reconnection of elements such that the gaps between them generate problems, fields of differential relations and singular points. Such teaching, however, is itself a form of learning, for it proceeds via an encounter with signs and an engagement with problems. To teach is to learn, finally, since for Deleuze genuine teaching and learning are simply names of genuine thought.

This approach to teaching movements, that is, an 'undoing of orthodox connection, and then a reconnection of elements', constitutes a truly unorthodox approach within sports and physical education contexts, where linear approaches and the position of the coach/teacher as the knowing subject is particularly strong (Denison and Mills, 2019; Larsson, 2003). It should be pointed out that this re-positioning of the knowing subject is not tantamount to an 'anything goes' perspective. Rather the opposite. A 'do it with me' approach probably demands more knowledge and experience from the pedagogue than the 'do as I do' approach.

In conclusion, we believe that Deleuze's theorising is largely compatible with notions of knowing-how (Ryle, 2009) and knowing (Polanyi, 1998). This is especially true concerning what Deleuze (1995) calls percepts, and the notion that learning is for the most part unconscious (cf. Polanyi's assertions about subsidiary awareness, and Ryle's notion of intelligent practice). In addition, mainly through the 'pedagogy of the concept' and the triadic relationship between affects, concepts and percepts (cf. Semetsky, 2009), we believe that Deleuze can add to Ryle's and Polanyi's ideas about knowing and learning, in particular concerning how these three constitute a whole, where every one of the constituent parts changes interdependently with changes in the other two. As was emphasised above, while in Ryle's and Polanyi's accounts, the significance of discovery is evident, we also believe that Deleuze, to a greater extent than Ryle and Polanyi, emphasises the simultaneous significance of discovery and invention when exploring a kinescape.

\section{Acknowledgements}

The authors wish to thank Zack and his peers for participating in our pedagogical module, and Lars Edström for planning and implementing the module in collaboration with us. We also wish to thank the two anonymous reviewers for important comments in connection with the completion of the article.

\section{Declaration of conflicting interests}

The author(s) declared no potential conflicts of interest with respect to the research, authorship and/or publication of this article. 


\section{Funding}

The author(s) disclosed receipt of the following financial support for the research, authorship and/or publication of this article: This work was supported by the Vetenskapsrådet (Grant No. 2017-03471).

\section{ORCID iDs}

Håkan Larsson (iD https://orcid.org/0000-0002-0638-7176

Dean Barker (D) https://orcid.org/0000-0003-4162-9844

\section{Notes}

1. Interestingly, Polanyi (1962) also uses swimming as an example of learning and knowing, in his case to illustrate the nature of tacit knowledge. The above quoted book by Deleuze (1994) was originally published in French in 1968. There is no reference to Polanyi in Deleuze's book. Nor does Polanyi refer to Deleuze.

2. This way of depicting the practice shows great resemblance with Bourdieu's description of logics of practice. According to Bourdieu (1990: 82), a participant's primary question is not 'why do I do this or that?' as a spectator would ask, but 'what do I do next?' According to Bourdieu, the latter question is, however, not approached from the perspective of a rational subject but from that of an embodied subject.

\section{References}

Aggerholm K (2016) On practising in sport: Towards an ascetological understanding of sport. Journal of the Philosophy of Sport 43(3): 350-364.

Angrosino MV (2005) Recontextualizing observation: Ethnography, pedagogy, and the prospects for a progressive political agenda. In: Denzin N and Lincoln Y (eds) Sage Handbook of Qualitative Research. Thousand Oaks, CA: Sage, 729-745.

Barker D, Bergentoft H and Nyberg G (2017) What would physical educators know about movement education? A review of literature, 2006-2016. Quest 69(4): 419-435.

Barker D, Nyberg G and Larsson H (2020a) Exploring movement learning in physical education using a threshold approach. Journal of Teaching in Physical Education 39(3): 415-423.

Barker D, Nyberg G and Larsson H (2020b) Joy, fear and resignation: Investigating emotions in physical education using a symbolic interactionist approach. Sport, Education and Society 25(8): 872-888.

Barker D, Nyberg G and Larsson H (2021) Coaching for skill development in sport: a kinesio-cultural approach. Sports Coaching Review, 1-18. iFirst, DOI:10.1080/17408989.2021.1886272

Beni S, Fletcher T and Ní Chróinín D (2017) Meaningful experiences in physical education and youth sport: A review of the literature. Quest 69(3): 291-312.

Bogue R (2004) Search, swim and see Deleuze's apprenticeship in signs and pedagogy of images. Educational Philosophy and Theory 36(3): 327-342.

Bäckström $\AA$ (2014) Knowing and teaching kinaesthetic experience in skateboarding: An example of sensory emplacement. Sport, Education and Society 19(6): 752-772.

Bäckström $\AA$ and Sand A-L (2019) Imagining and making material encounters: Skateboarding, Emplacement, and Spatial Desire. Journal of Sport and Social Issues 43(2): 122-142.

Cole DR (2016) Deleuze and learning. In: Peters MA (ed.) Encyclopaedia of Educational Philosophy and Theory. London: Sage, 1-6.

Coleman R and Ringrose J (2013) Introduction: Deleuze and research methodologies. In: Coleman R R and Ringrose J (eds) Deleuze and Research Methodologies. Edinburgh: Edinburgh University Press, 1-22.

Davids K (2010) The constraints-based approach to motor learning: Implications for a non-linear pedagogy in sport and physical education. In: Renshaw I, Davids K and Savelsbergh GJP (eds) Motor Learning in Practice. London and New York: Routledge, 23-36.

Deleuze G (1988) Foucault. Minneapolis: University of Minnesota Press. 
Deleuze G (1994) Difference and Repetition. London: Athlone.

Deleuze G (1995) Negotiations 1972-1990. New York: Columbia University Press.

Deleuze G (2000) Proust and Signs. The Complete Text. Minneapolis: University of Minnesota Press.

Deleuze G and Guattari F (1994) What is Philosophy? London: Verso.

Deleuze G and Guattari F (2013) Anti-Oedipus. Capitalism and Schizophrenia. London: Bloomsbury.

Denison J and Mills JP (2019) Problematizing practice: Coach development with foucault. In: Pringle R, Larsson H and Gerdin G (eds) Critical Research in Sport, Health and Physical Education. How to Make a Difference. London and New York: Routledge, 78-89.

Evans J (2004) Making a difference? Education and ability in physical education. European Physical Education Review 10(1): 95-108.

Fletcher T and Ní Chróinín D (2021) Pedagogical principles that support the prioritisation of meaningful experiences in physical education: Conceptual and practical considerations. Physical Education and Sport Pedagogy: 1-12, DOI: 10.1080/17408989.2021.1884672

Fusche Moe V (2004) How to understand skill acquisition in sport. Bulletin of Science, Technology \& Society 24(3): 213-224.

Grossberg L (1997) Bringing It All Back Home: Essays on Cultural Studies. Durham: Duke University Press. Hickey-Moody A (2013) Affect as method: Feelings, aesthetics and affective pedagogy. In: Coleman R and Ringrose J (eds) Deleuze and Research Methodologies. Edinburgh: Edinburgh University Press, 79-95.

Hirst PH (2010) Knowledge and the Curriculum: A Collection of Philosophical Papers. London: Routledge. Jess M, Atencio M and Thorburn M (2011) Complexity theory: Supporting curriculum and pedagogy developments in Scottish physical education. Sport, Education and Society 16(2): 179-199.

Landi D (2019) Queer men, affect, and physical education. Qualitative Research in Sport. Exercise and Health 11(2): $168-187$.

Larsson H (2003) A history of the present on the "sportsman" and the "sportswoman". Historical Social Research 31(1): 209-229.

Larsson H (2021) Learning Movements: New Perspectives of Movement Education. London and New York: Routledge.

Larsson H and Quennerstedt M (2012) Understanding movement: A sociocultural approach to exploring moving humans. Quest 64(4): 283-298.

Larsson H, Nyberg G and Barker D (2021) Juggling with gender. How gender promotes and prevents the learning of a specific movement activity among secondary school students. Gender and Education 33(5): 531546.

Lea J (2009) Becoming skilled: The cultural and corporeal geographies of teaching and learning Thai Yoga massage. Geoforum 40(3): 465-474.

Lupton D (2021) Next generation PE'? A sociomaterial approach to digitized health and physical education. Sport, Education and Society: 1-13. DOI: 10.1080/13573322.2021.1890570

Mazzei LA and McCoy K (2010) Thinking with Deleuze in qualitative research. International Journal of Qualitative Studies in Education 23(5): 503-509.

Nova N (2014) Beyond Design Ethnography. How Ethnographers Ethnographic Research. Rome: SHS Publishing.

Nyberg G and Larsson H (2014) Exploring 'what' to learn in physical education. Physical Education and Sport Pedagogy 19(2): 123-135.

Nyberg G, Barker D and Larsson H (2021) Learning in the educational landscapes of juggling, unicycling, and dancing. Physical Education and Sport Pedagogy 26(3): 279-292.

Polanyi M (1998) Personal Knowledge: Towards a Post-Critical Philosophy. Originally Published in 1958. Chicago: Chicago University Press.

Polanyi M (1962) Tacit knowing: Its bearing on some problems of philosophy. Reviews of Modern Physics 34(4): 601.

Ryle G (2009) The Concept of Mind. Originally Published in 1949. New York: Routledge. 
Safron S (2020a) Health, fitness, and affects in an urban after-school program. Sport, Education and Society 25(5): $556-569$.

Safron S (2020b) 'No perfect image': Health, fitness and visual affects with youth after-school. Physical Education and Sport Pedagogy 25(3): 225-239.

Semetsky I (2007) Towards a semiotic theory of learning: Deleuze's Philosophy and educational experience. Semiotica 164: 197-214.

Semetsky I (2009) Deleuze as a philosopher of education: Affective knowledge/effective learning. The European Legacy 14(4): 443-456.

Spradley JP (1979) The Ethnographic Interview. New York: Holt, Rinehart \& Winston.

Tidén A, Redelius K and Lundvall S (2017) The social construction of ability in movement assessment tools. Sport, Education and Society 22(6): 697-709.

Vannini P (2015) Non-representational methodologies: An introduction. In: Vannini P (ed.) Non-representational Methodologies: Re-Envisioning Research. London: Routledge, 1-18.

Whitehead M (2010) Physical Literacy. Throughout the Lifecourse. London and New York: Routledge.

\section{Author biographies}

Håkan Larsson is professor of Sport Science, Specialisation Education at The Swedish School of Sport and Health Sciences, Stockholm. His research is mainly within two research strands, critical pedagogy in sport and physical education and physical education didactics.

Gunn Nyberg is associate professor of Sport and Health Science, Specialisation Education at Dalarna University. Her research is mainly focused on knowledge, teaching and learning in physical education and sport.

Dean Barker is associate professor of Sport Science at the School of Health Sciences, Örebro University, Sweden. His research focuses on interaction and learning in physical education. 